\title{
A study of flow characteristics in a low-pressure ejector installation
}

\author{
Evgenia Varsegova ${ }^{1 *}[0000-0003-1890-3198]$, Lilia Osipova ${ }^{1[0000-0003-3336-1294]}$, and \\ DanielBugembe ${ }^{20000-0002-0677-4694]}$ \\ ${ }^{1}$ Kazan State University of Architecture and Engineering, 420043, Zelenaya st., 1, Kazan, Russia \\ ${ }^{2}$ Kazan National Research Technological University, 420015, Karl Marks st., 68, Kazan, Russia
}

\begin{abstract}
Production processes sometimes are accompanied by the release of hazardous substances, the composition and volume of which is determined by the production technology. When designing ventilation systems for paint departments, special attention is paid to safety concerns, since all paint coatings are corrosive and flammable substances. Besides, solvent vapors are explosive. For local ventilation of painting chambers, it is rational to use safe exhaust systems with an ejector, which works sturdily, regardless of the release of flammable and explosive impurities. The ejector is simple in design and can operate in a wide range of changes in the parameters of the state of airflow. The model of the ejection unit is synthesized using the universal modeling package ChemCad, which contains a highly developed database of airflow parameters, which allows for solving various applied problems. Numerical modeling was carried out using the software package - FLUENT. In work, a calculation was carried out and a low-pressure ejector was designed for a typical painting booth. The calculation results are presented in the form of graphs and tables of pressures, velocities, flow rates in characteristic sections, pressure losses in the sections of the ejector installation. The ejection coefficient was also calculated.
\end{abstract}

Keywords: Heat supply, ventilation, air conditioning, gas supply, and lighting.

\section{Introduction}

There are known studies in which to stabilize the operation of the exhaust ventilation system of buildings for various purposes it is proposed to design modular ejection systems [1-6].

When designing industrial ventilation, supply and exhaust systems are used based on the operation of fans. Such solutions are quite sufficient in assembly, packaging, and filling shops of industries that are not associated with the release of pollutants, and where the main task of ventilation is the comfortable stay of the working personnel in the room. If the production process is associated with the release of a large amount of heat, moisture, dust, flammable and explosive substances, then when designing ventilation systems, it is

*Corresponding author:evgeniyav09@gmail.com 
necessary to take into account the peculiarities of the production technology [7-9] and the danger of using fans. In cases where the exhaust air contains explosive or destructive impurities acting on the fan, for example, in painting booths or in chamber dryers, when it is required to create insignificant dynamic pressures for the circulation of airflow, it is rational to use safe exhaust systems with an ejector. At the same time, ejection systems have low efficiency and therefore are used when other solutions are not possible. In the studies [10-11], a description and study of exhaust ventilation systems is given, where ejector installations have been used that work reliably, regardless of the volume of released flammable, explosive, and abrasive impurities.

Methods for calculating ejectors are well developed, but they do not allow for designing optimal solutions with minimal energy consumption. Problems of this kind are effectively solved using various modeling applications. In particular, the use of the ChemCad universal modeling program (UMP) allows for the calculating of the thermophysical properties of air flows with various contaminants. In [12-13] examples of solving applied problems using the UMP ChemCad are considered.

Computational fluid dynamics methods using the ANSYS (FLUENT) software package are also widely used to solve such applied problems [14-18]. Numerical methods make it possible to quickly and visually simulate the flow of air flows in characteristic sections of an ejector installation and design more efficient industrial ventilation systems [19-22].

\section{Materials and methods}

In this work, the object of research is a low-pressure ejector unit (Fig. 1). The ejection effect consists in the fact that the ejected stream (active), of high pressure, moves at a high speed, carries along with it the ejected stream (passive) of low pressure. Clean air, blown by a high-pressure fan 5 located outside the ventilated room, flows out of nozzle 1 into the mixing chamber 3 , into which air from the receiving chamber 2 of the manned room is sucked in due to the pressure difference. Further, the mixture of active and passive streams flows through the diffuser 4 , and the air duct and is discharged into the atmosphere.

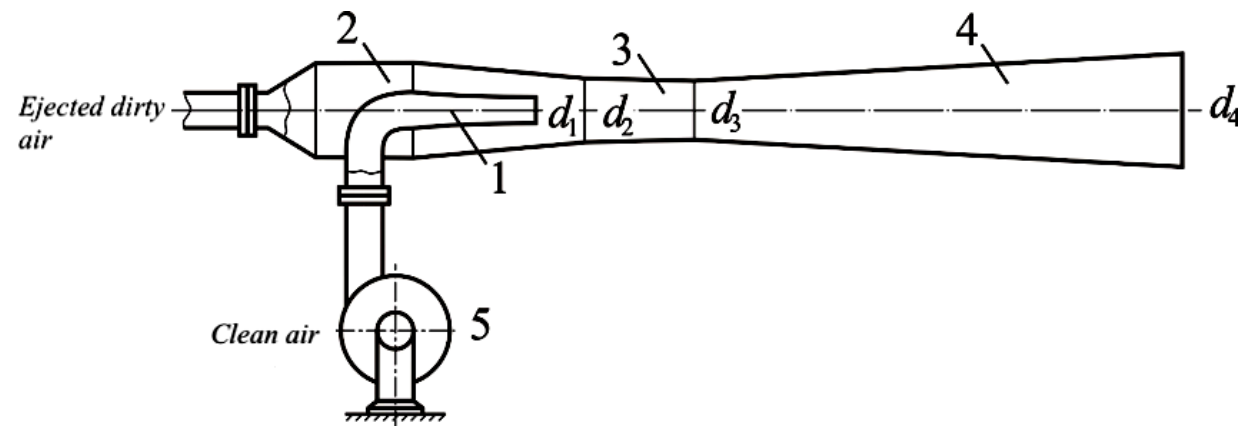

Fig. 1. Scheme of the ejector installation: 1 - nozzle; 2 - receiving chamber;3 - mixing chamber; 4 diffuser; 5 - fan.

For painting a variety of products - from small parts to large-sized products, paint booths are designed. When simulating a low-pressure ejector, a painting booth with a size of $5.4 *$ $3.4 * 2.5 \mathrm{~m}^{3}$ was considered. The air is supplied from the top, evenly over the entire area of the false ceiling. Air suction is carried out in the center of the chamber, through the floor, which is equipped with floor grilles throughout the entire area. The inlet and outlet pass through a cleaning system. The minimum temperature is $20-25^{\circ} \mathrm{C}$ (in the drying mode up to $50^{\circ} \mathrm{C}$ ). Air movement in the painting area is $20-25 \mathrm{~cm} / \mathrm{s}$. The air pressure in the chamber is slightly higher than the standard $100 \mathrm{kPa}$ (atmospheric pressure or outside pressure). 
For the calculation, the amount of air supply was taken as $6600 \mathrm{~m}^{3} / \mathrm{h}$. To ensure the back pressure, it is required to remove $6000 \mathrm{~m}^{3} / \mathrm{h}$ of air with the resistance of the suction network $\Delta p_{2}=230 \mathrm{~Pa}$; the resistance of the pressure head of the ejector $\Delta p_{3}=80 \mathrm{~Pa}$; stirring factor $w=1$.

When designing equipment based on the principles of ejection, it is necessary to determine the optimal shape and geometric dimensions of the ejector, as well as the characteristics of the fan, taking into account that the power consumed by its electric drive determines a significant share of the costs of the painting process.

The main design parameter of the ejector is the ejection coefficient, which is understood as the ratio of the flow rate of the active (blown by the fan) stream to the flow of the passive stream (sucked in from the painting chamber). The higher the ejection coefficient, the lower the flow rate of the supplied active stream, and, thus, the less electricity is consumed by the fan. The ejection coefficient itself is a function that depends on the geometric characteristics of the ejector, therefore, finding the optimal geometry of the ejector will reduce both operating and capital costs for installing the ventilation system.

The main purpose of calculating the ejector installation in this work is to obtain the values of pressures and velocities at any point of the model, flow rates at the boundaries, and also to calculate the ejection coefficient:

$$
\text { . } \beta=G_{\mathrm{C}} / G_{\mathrm{D}}
$$

Where $G_{\mathrm{D}}$ - flow rate of the ejected (dirty) air; $G_{\mathrm{C}}$ - flow of ejecting (clean) air, $\mathrm{kg} / \mathrm{s}$.

\subsection{Low-pressure ejector simulation}

In the simulation, the ejector is divided into three parts: a nozzle, a mixing chamber, and a diffuser (Fig. 1). (3):

The pressure and temperature at the nozzle exit are determined by the equations (2) and

$$
\begin{gathered}
\frac{P_{1}}{P_{2}}=\left[1+\frac{\gamma-1}{2} M^{2}\right]^{\frac{\gamma}{\gamma-1}}, \\
\frac{T_{1}}{T_{2}}=1+\frac{\gamma-1}{2} M^{2} .
\end{gathered}
$$

The main equation used in the simulation of the ejector:

$$
\frac{A_{2}}{A_{c}}=\sqrt{\frac{\left[\left(\frac{2}{1+\gamma_{1}}\right)\left(1+\frac{\gamma_{1}-1}{2} M_{2}^{2}\right)\right]^{\frac{\gamma_{1}+1}{\gamma_{1}-1}}}{M_{2}^{2}}} .
$$

The nozzle outlet pressure is calculated as follows:

$$
P_{2}=\frac{P_{1}}{\left[\frac{\gamma_{1}-1}{2 \eta_{c}} M_{2}^{2}+1\right]^{\frac{\gamma_{1}}{\gamma_{1}-1}}} .
$$

Nozzle outlet temperatures:

The speed of sound:

$$
T_{2}=\frac{T_{1}}{1+\frac{\gamma_{1}-1}{2 \eta_{c}} M_{2}^{2}}
$$

$$
C_{2}=\sqrt{\gamma_{1} R_{1} T_{2}}
$$

Actual flow rate:

$$
V_{2}=C_{2} M_{2}
$$


The Mach number before mixing the active and ejected streams in the nozzle is expressed by the formula:

$$
M_{v_{2}}=\sqrt{\frac{2}{\gamma_{2}-1}\left[\left(\frac{P_{v}}{P_{2}}\right)^{\frac{\gamma_{2}-1}{\gamma_{2}}}-1\right]} .
$$

In general, to obtain the critical Mach number in any section $i$, the following equation can be used:

$$
M_{i}^{*}=\sqrt{\frac{M_{i}^{2}(\gamma+1)}{M_{i}^{2}(\gamma-1)+2}} .
$$

If we take into account equation (10), then the critical Mach number at the nozzle exit is calculated by the formula:

$$
M_{2}^{*}=\sqrt{\frac{M_{2}^{2}\left(\gamma_{2}+1\right)}{M_{2}^{2}\left(\gamma_{2}-1\right)+2}} .
$$

By definition, the ratio for the ejection coefficient is calculated by the formula:

$$
w=\frac{m_{v}}{m_{1}} .
$$

The critical Mach number of the moving stream at the outlet from the nozzle before mixing with the ejected stream:

$$
M_{v_{2}}^{*}=\sqrt{\frac{M_{v_{2}}^{2}\left(\gamma_{1}+1\right)}{M_{v_{2}}^{2}\left(\gamma_{1}-1\right)+2}} .
$$

When simulating the mixing process, one-dimensional continuity equations in combination with the equations of motion and energy can be combined into the following relations to calculate the critical Mach number and Mach number in the diffuser:

$$
\begin{gathered}
M_{4}^{*}=\frac{M_{2}^{*}+w M_{v_{2}}^{*} \sqrt{\frac{T_{v}}{T_{1}}}}{\sqrt{(1+w)\left(1+w \frac{T_{v}}{T_{1}}\right)}}, \\
M_{4}=\frac{\sqrt{2} M_{4}^{*}}{\sqrt{\left(\gamma_{3}+1\right)-M_{4}^{* 2}\left(\gamma_{3}-1\right)}} .
\end{gathered}
$$

To calculate the mixed active and ejected flow before the exhaust, the following equation is used:

$$
T_{4}=\frac{T_{2}}{1+\frac{\gamma_{3}-1}{2} M_{4}^{2}} .
$$

Mach number at the entrance and exit of the diffuser:

$$
\begin{gathered}
M_{5}=\sqrt{\frac{M_{4}^{2}+\frac{2}{\gamma_{3}-1}}{\frac{2 \gamma_{3}}{\gamma_{3}-1} M_{4}^{2}-1},} \\
M_{3}=\sqrt{\frac{M_{5}^{2}+\frac{2}{\gamma_{3}-1}}{\gamma_{3}-1} M_{5}^{2}-1} .
\end{gathered}
$$

It should be noted that the following equations are used to calculate the temperature and pressure at the diffuser inlet:

$$
T_{3}=\frac{T_{2}}{1+\frac{\gamma_{1}-1}{2} M_{3}^{2}},
$$




$$
P_{3}=\frac{P_{2}}{\left(1+\frac{\gamma_{3}-1}{2} M_{3}^{2}\right)^{\frac{\gamma_{3}}{\gamma_{3}-1}}} .
$$

The speed of sound and the actual speed are determined by the following relationships:

$$
\begin{gathered}
C_{3}=\sqrt{\gamma_{3} R_{3} T_{3}}, \\
C_{4}=\sqrt{\gamma_{3} R_{3} T_{4}}, \\
V_{3}=C_{3} M_{3}, \\
V_{4}=C_{4} M_{4} .
\end{gathered}
$$

The temperature and pressure at the outlet of the diffuser are calculated as follows:

$$
\begin{aligned}
& T_{5}=\frac{1+\frac{\gamma_{3}-1}{2} M_{4}^{2}}{1+\frac{\gamma_{3}-1}{2} M_{5}^{2}}, \\
& P_{5}=\frac{1+\gamma_{3} M_{4}^{2}}{1+\gamma_{3} M_{5}^{2}} P_{4} .
\end{aligned}
$$

In order to calculate the outlet pressure from the ejector, we can use the following equations:

$$
\begin{gathered}
\frac{A_{1}}{A_{d}}=\frac{P_{6}}{P_{1}}\left(\frac{1}{(1+w)\left(1+w \frac{T_{v}}{T_{1}}\right)}\right)^{1 / 2} \cdot \frac{\left(\frac{P_{2}}{P_{6}}\right)^{\frac{1}{\gamma_{1}}} \cdot\left(1-\left(\frac{P_{2}}{P_{6}}\right)^{\frac{\gamma_{1}-1}{\gamma_{3}}}\right)^{1 / 2}}{\left(\frac{2}{\gamma_{1}+1}\right)^{\frac{1}{\gamma_{3}-1}} \cdot\left(1-\frac{2}{\gamma_{3}+1}\right)^{1 / 2}}, \\
P_{6}=P_{5}\left(\eta_{d} \frac{\gamma_{3}-1}{2} M_{5}^{2}+1\right)^{\frac{\gamma_{3}}{\gamma_{3}-1}} \cdot
\end{gathered}
$$

Thus, the output stream from the ejector is:

$$
m_{6}=m_{1}+m_{v} \text {. }
$$

Equations (2) - (29) allow to calculate the ejector for a given performance. Problems of this kind are effectively solved using various modulating application programs. In particular, the use of the ChemCad universal modeling program (UMP) makes it possible to calculate the thermophysical properties of air streams with volatile components of various paints and varnishes. In [12-13] examples of solving applied problems using the UMP ChemCad are considered.

Equations (2)-(29) were inputted into the ejector calculation algorithm for various operating modes (using the DataMap toolkit).

\subsection{A numerical study of the flow in a low-pressure ejector system}

A numerical study of the flow in a low-pressure ejector system was carried out using the licensed software package ANSYS ${ }^{\circledR}$ Academic Research Mechanical and CFD, Release 18.2. The system of differential equations of turbulent motion is closed using the «standard» $k-\varepsilon$ model ( $k$ - kinetic energy of turbulent pulsations, $\varepsilon$ - specific dissipation of turbulent energy). For modeling the boundary layer near impermeable surfaces, the Standard Wall Function is adopted.

Limit conditions:

- at the inlet of the ejected (dirty) air, the flow rate $G_{\mathrm{D}}$ was set, $\mathrm{kg} / \mathrm{s}$;

- at the inlet of the ejecting (clean) air, the excess pressure $P_{n}$, created by the pump was set, $\mathrm{Pa}$;

- excess pressure $P_{\text {out }}, \mathrm{Pa}$ was set at the outlet from the ejector unit. 


\section{Results}

In fig. 2 the design diagram of the ejector in the UMP ChemCad is shown. Square contours denote flows, where 1 - passive stream (PS); 2 - gas at the suction pipe of the ejector; 3 - a mixture of AS and PS; 4 - gas at the outlet of the ejector; 5, 6 - active stream (AS). Circular contours indicate the modules of the calculation scheme that simulate an ejector and a fan, where module 3 (Mixer) is a mixer that mixes the input flows at a given outlet pressure; module 1 (Pump) - fan; module 2 (Valve) - simulates the pressure drop across the suction line; Module 4 (Valve) - simulates an increase in pressure in the ejector outlet cone.

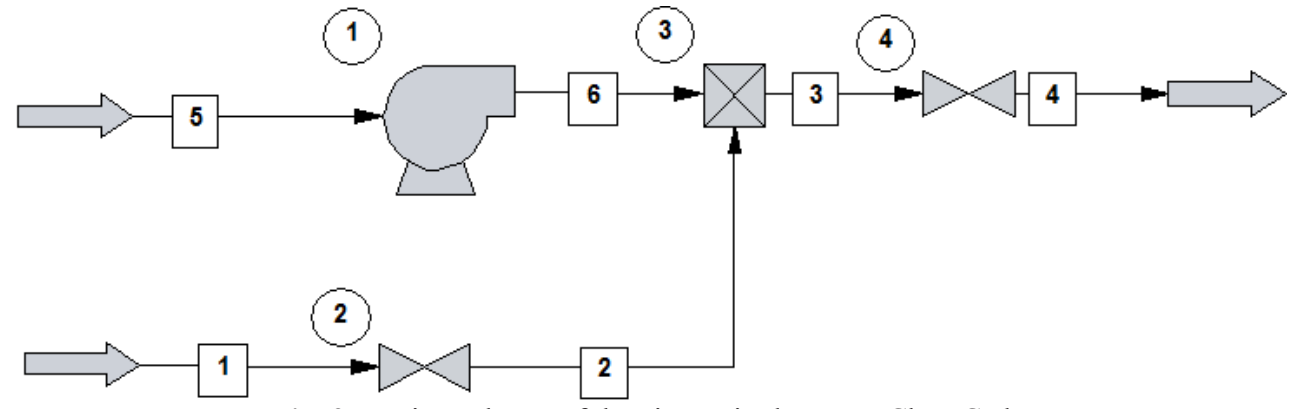

Fig. 2. Design scheme of the ejector in the UMP ChemCad.

The table shows the geometrical dimensions and parameters of the ejector for a capacity of $6000 \mathrm{~m}^{3} / \mathrm{s}$, which can be recommended for ventilation of a painting booth with a size of $5.4 * 3.4 * 2.5 \mathrm{~m}^{3}$ :

Table 1. Ejector parameters.

\begin{tabular}{|l|c|}
\hline \multicolumn{1}{|c|}{ Ejector parameter } & Geometric size, $\mathrm{mm}$ \\
\hline Diameter of the outlet section of the nozzle, $d_{1}$ & 211 \\
\hline Diameter of the beginning of the mixing chamber, $d_{2}$ & 470 \\
\hline Ejectorthroatdiameter, $d_{3}$ & 376 \\
\hline Diffusermouthdiameter, $d_{4}$ & 800 \\
\hline Suctiondiameter, $d_{\text {suc }}$ & 560 \\
\hline Pressurepipelinediameter, $d_{\mathrm{p}}$ & 500 \\
\hline Mixingchamberlength, $l_{\text {chem }}$ & 1320 \\
\hline Diffuserlength, $l_{\text {dif }}$ & 4240 \\
\hline Height of the cylindrical part of the nozzle, $\mathrm{G}$ & 106 \\
\hline Nozzleconfuserheight, $\mathrm{E}$ & 422 \\
\hline $\begin{array}{l}\text { Distance from the center of the pressure air duct to the bottom of } \\
\text { the receiving chamber, } \mathrm{Z}\end{array}$ & 500 \\
\hline Receivingchamberheight, $\mathrm{K}$ & 1000 \\
\hline Receivingchamberdiameter, $\mathrm{L}$ & 1000 \\
\hline Intake chamber diffuser length, M & 560 \\
\hline Length of the confuser of the receiving chamber, I & 528 \\
\hline
\end{tabular}

It is proposed to install a fan of the VTs5-35-8V1.01 brand, an AIM132M4 electric motor, and power consumption of $11 \mathrm{~kW}$ to the ejector. The rotational speed is $1500 \mathrm{rpm}$, the developed total pressure is $2900-2060 \mathrm{~Pa}$.

Table 2. Calculation of low pressure ejector.

\begin{tabular}{|l|c|c|l|}
\hline Parameter name & Designation & Value & Unit \\
\hline Secondary volume of evacuated air & $\mathrm{L} 2$ & 1.6667 & $\mathrm{~m}^{3} / \mathrm{s}$ \\
\hline Second volume of ejected air & $\mathrm{L} 1$ & 1.6667 & $\mathrm{~m}^{3} / \mathrm{s}$ \\
\hline
\end{tabular}




\begin{tabular}{|c|c|c|c|}
\hline Mixed air volume per second & L3 & 3.3333 & $\mathrm{~m}^{3} / \mathrm{s}$ \\
\hline $\begin{array}{l}\text { The efficiency of the diffuser is } \eta_{\text {diff }}=0.65 \text {, which at } \beta=1 \\
\text { corresponds to the optimal speed ratio }\end{array}$ & $\mathrm{n}$ & 0.4 & \\
\hline Air velocity U3 after mixing flows in the ejector & U3 & 20.6 & $\mathrm{~m} / \mathrm{s}$ \\
\hline Air velocity in the throat of the ejector & U'3 & 27.8 & $\mathrm{~m} / \mathrm{s}$ \\
\hline Air velocity when leaving the nozzle & U1 & 44.5 & $\mathrm{~m} / \mathrm{s}$ \\
\hline Mixingflowrate & $\mathrm{U} 2$ & 11.15 & $\mathrm{~m} / \mathrm{s}$ \\
\hline The area of the outlet section of the nozzle & f1 & 0.0375 & $\mathrm{~m}^{2}$ \\
\hline Diameter of the outlet section of the nozzle & $d_{1}$ & 0.2187 & $\mathrm{~m}$ \\
\hline $\begin{array}{l}\text { Annular cross-sectional area between the mixing chamber wall } \\
\text { and the nozzle }\end{array}$ & $f^{\prime} 2$ & 0.1495 & $\mathrm{~m}^{2}$ \\
\hline Sectional area at the beginning of the mixing chamber & $\mathrm{f} 2$ & 0.1869 & $\mathrm{~m}^{3}$ \\
\hline Mixingchamberstartdiameter & $d_{2}$ & 0.4886 & $\mathrm{~m}$ \\
\hline Ejectorthroatarea & $\mathrm{f3}$ & 0.1199 & $\mathrm{~m}^{2}$ \\
\hline Ejectorthroatdiameter & $d_{3}$ & 0.3913 & $\mathrm{~m}$ \\
\hline Mixingchamberdiameter & $l_{\text {chem }}$ & 1.9345 & $\mathrm{~m}$ \\
\hline Mixingchamberfrictionresistance & $\Delta p_{\text {chem }}$ & 2.5467 & $\mathrm{~kg} / \mathrm{m}^{2}$ \\
\hline $\begin{array}{l}\text { The diameter of the diffuser mouth is taken from the speed } \\
\text { conditions of } 4-8 \mathrm{~m} / \mathrm{s}\end{array}$ & $d_{4}$ & 0.8 & $\mathrm{~m}$ \\
\hline Diffusermouthspeed & U4 & 6.6348 & $\mathrm{~m} / \mathrm{s}$ \\
\hline Diffuserlength & $l_{\text {dif }}$ & 4.0871 & $\mathrm{~m}$ \\
\hline Diffuserfrictionresistance & $\Delta p_{\text {dif }}$ & 2.4237 & $\mathrm{~kg} / \mathrm{m}^{2}$ \\
\hline Total resistance of the pressure head of the ejector & $\Delta p_{3}$ & 6.9304 & $\mathrm{~kg} / \mathrm{m}^{2}$ \\
\hline Back-up pressure in case of installation of an exhaust shaft & $\Delta p_{\text {shaft }}$ & 1.0696 & $\mathrm{~kg} / \mathrm{m}^{2}$ \\
\hline Nozzleheight & $\mathrm{G}$ & 0.1093 & $\mathrm{~m}$ \\
\hline Nozzleconfuserheight & $\mathrm{E}$ & 0.4374 & $\mathrm{~m}$ \\
\hline $\begin{array}{l}\text { Radius of curvature of the pressure air duct at the entrance to } \\
\text { the receiving chamber }\end{array}$ & $r=d_{\mathrm{p}}$ & 0.5 & $\mathrm{~m}$ \\
\hline The speed of the ejected air in the pressure air duct & $\mathrm{U}_{\mathrm{p}}$ & 8.4926 & $\mathrm{~m} / \mathrm{s}$ \\
\hline $\begin{array}{l}\text { Distance from the center of the pressure air duct to the } \\
\text { receiving chamber }\end{array}$ & $\mathrm{Z}=d_{\mathrm{p}}$ & 0.5 & $\mathrm{~m}$ \\
\hline Length of the confuser of the receiving chamber & $\mathrm{I}=2,5 d_{1}$ & 0.5467 & $\mathrm{~m}$ \\
\hline Receivingchamberheight & $\begin{array}{c}\mathrm{K}=\mathrm{J}+3= \\
2 d_{\mathrm{H}}\end{array}$ & 1 & $\mathrm{~m}$ \\
\hline Receivingchamberdiameter & $\mathrm{L}=\mathrm{K}=2 d_{\mathrm{H}}$ & 1 & $\mathrm{~m}$ \\
\hline Intakechamberdiffuserlength & $\mathrm{M}=d_{\text {in }}$ & 0.56 & $\mathrm{~m}$ \\
\hline The speed of the ejected air in the intake duct & $\mathrm{U}_{\mathrm{B} 2}$ & 6.7702 & $\mathrm{~m} / \mathrm{s}$ \\
\hline Dynamic pressure in the annular section of the chamber & $\Delta p_{\text {dyn } 2}$ & 7.75 & $\mathrm{~kg} / \mathrm{m}^{2}$ \\
\hline Vacuum at the beginning of the mixing chamber & $\Delta p_{\text {vac }}$ & 27.75 & $\mathrm{~kg} / \mathrm{m}^{2}$ \\
\hline Dynamic pressure at the outlet of the nozzle & $\Delta p_{\text {dyn1 }}$ & 123.77 & $\mathrm{~kg} / \mathrm{m}^{2}$ \\
\hline Full pressure at the outlet of the nozzle & $\Delta p_{1}$ & 96.016 & $\mathrm{~kg} / \mathrm{m}^{2}$ \\
\hline Pressure network resistance to nozzle & $\Delta p_{\text {to noz. }}$ & 25.25 & $\mathrm{~kg} / \mathrm{m}^{2}$ \\
\hline Total pressure generated by the fan & $\Delta p_{\text {fan }}$ & 139.83 & $\mathrm{~kg} / \mathrm{m}^{2}$ \\
\hline Static efficiency of the ejector & $\mathrm{n}_{\mathrm{st}}$ & 29.162 & $\%$ \\
\hline
\end{tabular}

We convert the pressures in Pascal (table 3).

Table 3. Converted pressure values.

\begin{tabular}{|c|c|c|c|}
\hline Parameter name & Designation & Value & Unit \\
\hline Mixingchamberfrictionresistance & $\Delta p_{\text {chem }}$ & 24.974 & $\mathrm{~Pa}$ \\
\hline
\end{tabular}




\begin{tabular}{|l|c|c|c|}
\hline Diffuserfrictionresistance & $\Delta p_{\text {dif }}$ & 23.768 & $\mathrm{~Pa}$ \\
\hline Total resistance of the pressure head of the ejector & $\Delta p_{3}$ & 67.964 & $\mathrm{~Pa}$ \\
\hline $\begin{array}{l}\text { Back-up pressure in case of installation of an } \\
\text { exhaust shaft }\end{array}$ & $\Delta p_{\text {shaft }}$ & 10.489 & $\mathrm{~Pa}$ \\
\hline $\begin{array}{l}\text { Dynamic pressure in the annular section of the } \\
\text { chamber }\end{array}$ & $\Delta p_{\text {dyn2 }}$ & 76.001 & $\mathrm{~Pa}$ \\
\hline Vacuum at the beginning of the mixing chamber & $\Delta p_{\text {vac }}$ & 272.134 & $\mathrm{~Pa}$ \\
\hline Dynamic pressure at the outlet of the nozzle & $\Delta p_{\text {dyn1 }}$ & 1213.769 & $\mathrm{~Pa}$ \\
\hline Full pressure at the outlet of the nozzle & $\Delta p_{1}$ & 941.595 & $\mathrm{~Pa}$ \\
\hline Pressure network resistance to nozzle & $\Delta p_{\text {to noz }}$ & 247.617 & $\mathrm{~Pa}$ \\
\hline Total pressure generated by the fan & $\Delta p_{\text {fan }}$ & 1371.263 & $\mathrm{~Pa}$ \\
\hline
\end{tabular}

We select the fan according to the pressure created by the fan. In our case, V4-10D and V3$10 \mathrm{a}$ are suitable, which create a pressure of $140 \mathrm{~kg} / \mathrm{m}^{2}$.

The results of the numerical calculation of the ejector installation are presented in tables 4-6 and Fig. 3. The purpose of the calculation was to determine the pressure, velocities, flow rates in characteristic sections, pressure losses in the sections of the ejector installation, and also to calculate the ejection coefficient. The calculation results are presented in Tables 2-4 and Figs 2-3.

Table 4. Values of the found parameters in the characteristic sections of the ejector installation.

\begin{tabular}{|c|c|c|c|c|c|c|}
\hline $\mathrm{N}$ & Boundaries & $\begin{array}{c}\text { Flow } \\
\text { rate } \\
G, \\
\mathrm{~kg} / \mathrm{s} \\
\end{array}$ & $\begin{array}{c}\text { Speed } \\
V, \mathrm{~m} / \mathrm{s}\end{array}$ & $\begin{array}{c}\text { Excess } \\
\text { static } \\
\text { pressure, } \\
P, \mathrm{~Pa}\end{array}$ & $\begin{array}{c}\text { Excess } \\
\text { dynamic } \\
\text { pressure, } \\
P_{\mathrm{d}}, \mathrm{Pa} \\
\end{array}$ & $\begin{array}{c}\text { Excess } \\
\text { total } \\
\text { pressure, } \\
P_{\mathrm{t}}, \mathrm{Pa} \\
\end{array}$ \\
\hline \multirow{6}{*}{1.} & Dirtyairinlet & 2 & 4.3 & 0 & 11.36 & 11.36 \\
\hline & Cleanairinlet & 2.4 & 5 & 1470 & 15 & 1485 \\
\hline & Cleanairoutlet & 4.4 & 57.8 & -759.40 & 2051.5 & 1292.10 \\
\hline & Flowmixingline & 4.4 & 47.78 & -898.48 & 1459.26 & 560.78 \\
\hline & $\begin{array}{l}\text { The beginning of } \\
\text { the diffuser }\end{array}$ & 4.4 & 59.53 & -1625.69 & 2185.05 & 559.36 \\
\hline & Exit & 4.4 & 27.7 & 0 & 500 & 500 \\
\hline \multirow{6}{*}{2.} & Dirtyairinlet & 2 & 4.3 & 0 & 11.64 & 11.64 \\
\hline & Cleanairinlet & 2.64 & 5.1 & 1784 & 16 & 1800 \\
\hline & Cleanairoutlet & 4.64 & 60.42 & -668.41 & 2240.82 & 1572.41 \\
\hline & Flowmixingline & 4.64 & 47.77 & -800.10 & 1523.12 & 723.02 \\
\hline & $\begin{array}{l}\text { The beginning of } \\
\text { the diffuser }\end{array}$ & 4.64 & 59.53 & -1470.24 & 2156.84 & 686.60 \\
\hline & Exit & 4.64 & 27.7 & 0 & 500 & 500 \\
\hline \multirow{6}{*}{3.} & Dirtyairinlet & 2 & 4.3 & 0 & 11.09 & 11.09 \\
\hline & Cleanairinlet & 2.15 & 2.56 & 1196 & 4 & 1200 \\
\hline & Cleanairoutlet & 4.15 & 55.2 & -856.17 & 1867.73 & 1011.56 \\
\hline & Flowmixingline & 4.15 & 47.8 & -1002.76 & 1526.07 & 532.31 \\
\hline & $\begin{array}{l}\text { The beginning of } \\
\text { the diffuser }\end{array}$ & 4.15 & 59.5 & -1774.96 & 2280.78 & 505.82 \\
\hline & Exit & 4.15 & 27.7 & 0 & 500 & 500 \\
\hline
\end{tabular}

A fan is selected according to the specified pressure at the inlet of clean air (Table 2) according to the designer's manual. In the performed numerical experiments, fans of models V-Ts14-46-4-04 and V-Ts4-70-4-01 can be used.

Table 5. Values of the ejection coefficients of the installation. 


\begin{tabular}{|c|c|c|}
\hline Dirty air flow rate $G_{\mathrm{D}}, \mathrm{kg} / \mathrm{s}$ & Clean air flow rate $G_{\mathrm{c}}, \mathrm{kg} / \mathrm{s}$ & Ejectioncoefficient $\beta$ \\
\hline 2 & 2.4 & 1.2 \\
\hline 2 & 2.64 & 1.32 \\
\hline 2 & 2.15 & 1.08 \\
\hline
\end{tabular}

Table 6. Losses of total pressures in the sections of the ejector installation.

\begin{tabular}{|c|l|c|}
\hline \multirow{2}{*}{$\mathrm{N}$} & \multicolumn{1}{|c|}{ Section } & $\begin{array}{c}\text { Total pressure loss, } \Delta P, \\
\mathrm{~Pa}\end{array}$ \\
\hline \multirow{3}{*}{1.} & Pressure pipeline (from inlet to outlet of dirty air) & 193 \\
\cline { 2 - 3 } & Intake duct (from dirty air inlet to mixing line) & 74.81 \\
\cline { 2 - 3 } & Inthediffuser & 59.36 \\
\hline \multirow{2}{*}{2.} & Pressure pipeline (from inlet to outlet of dirty air) & 227.59 \\
\cline { 2 - 3 } & Intake duct (from dirty air inlet to mixing line) & 70.55 \\
\cline { 2 - 3 } & Inthediffuser & 186.6 \\
\hline \multirow{3}{*}{3.} & Pressure pipeline (from inlet to outlet of dirty air) & 188.44 \\
\cline { 2 - 3 } & Intake duct (from dirty air inlet to mixing line) & 79.56 \\
\cline { 2 - 3 } & Inthediffuser & 5.82 \\
\hline
\end{tabular}

Fig. 3 shows a qualitative picture of the distribution of velocities and pressures in the ejector.

a)
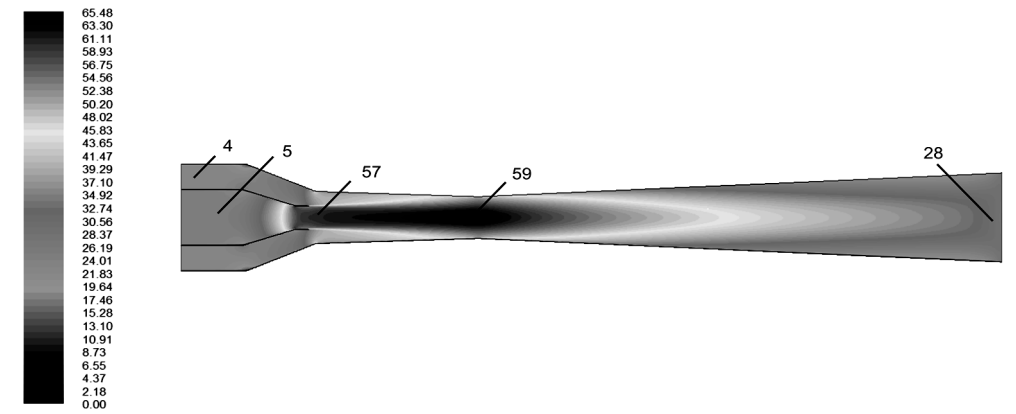

b)
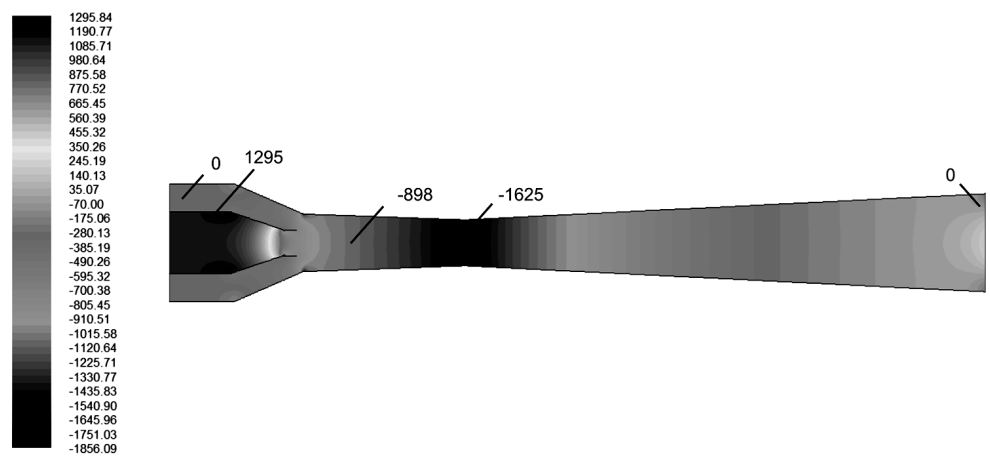

Fig. 3. Distributed characteristics of the ejector installation (illustration by the authors): velocity distribution, $\mathrm{m} / \mathrm{s}$; b) the distribution of excess static pressure, $\mathrm{Pa}$.

\section{Discussion}


The unit is used to house a painting booth with internal dimensions of $5.4 \times 3.4 \times 2.5 \mathrm{~m}$, where mechanical exhaust ventilation is provided by the ejection method. The flow rate of the removed dirty air is $2 \mathrm{~kg} / \mathrm{s}$, which corresponds to $6000 \mathrm{~kg} / \mathrm{h}$. From the designer's handbook «Internal sanitary devices. Ventilation and air conditioning», a typical ejection installation was selected, the geometric dimensions of which are presented in table 1 and several variants of centrifugal fans have been selected for it.

The $\beta$ coefficient turned out to be slightly more than one, which indicates a fairly efficient operation of the ejection installation. In the case of $\beta>1$, the dirty air is purified by mixing in a significant amount of clean air. The optimal ejection coefficient lies in the range from $0.5-1$, which corresponds to the high efficiency of the ejection device.

\section{Conclusions}

1. Since all paints and varnishes are flammable substances, it is advisable to use an ejection exhaust ventilation system when designing ventilation for painting chambers (both new and those to be reconstructed).

2. Using the DataMap toolkit (an embedded function of the UMP ChemCad), which connects the universal simulator with a user file, it is possible to integrate the thermophysical properties of flows into formulas (2) - (29), thereby automating the calculation process.

3. In the work, a numerical study of the airflow in a low-pressure ejector installation has been carried out. Changes in pressures, velocities, and flow rates at the inlet and outlet of the low-pressure ejector and pressure losses in different sections of the ejector were determined.

4. The ejection coefficient $\beta$ was determined, it turned out to be slightly more than one, which indicates a fairly efficient operation of the ejector installation. Anaccurately calculated ejection coefficient significantly increases the energy efficiency of the room ventilation system.

5. The results obtained in the article can be recommended for calculation in the design of ejector installations of industrial ventilation systems, including the optimal operating mode of the fan based on the pressure losses found.

\section{List of designations}

$P$ - pressure, $\mathrm{kPa} ; T$ - temperature, ${ }^{\circ} \mathrm{K} ; A$ - cross-sectional area, $\mathrm{m}^{2} ; \gamma$-adiabatic index; $C$ - speed of sound, $\mathrm{m} / \mathrm{s} ; V$ is the actual speed, $\mathrm{m} / \mathrm{s} ; M$ - Mach criterion; $R$ - universal gas constant, $\mathrm{kJ} /\left(\mathrm{kg}{ }^{\circ} \mathrm{K}\right) ; w-$ ejection coefficient; $\eta$ - efficiency; $m$ - mass flow rate, $\mathrm{kg} / \mathrm{s}$.

\section{Indexes}

$v$ - parameters of the passive stream; 1 - parameters of the active stream; 2 - parameters at the nozzle exit; 3 - parameters of the mixed stream; 4 - parameters before entering the diffuser; 5 - parameters at the outlet of the diffuser; 6 - parameters at the outlet of the ejector; $c$-parameters related to the nozzle; $d$ - parameters related to the diffuser; ${ }^{*}$ - critical parameters.

\section{References}

1. W. Sujatmiko, H. K. Dipojono, F.X. Nugroho,F.X.N. Soelami, Soegijanto, Procedia. Environmental Sciences, 28, 360-369 (2015) DOI: 10.1016/j.proenv.2015.07.045

2. W. Sujatmiko, H. K. Dipojono, Soegijanto, and F. X. N. Soelami, The effect of passive system on thermal comfort in high rise building flats - a case study in Bandung, in The Int. Conference: Sustainable built environment in tropics: New technology, new behavior, School of Architecture, Tarumanegara University, Jakarta, 12-13 November (2012) 
3. A. S. Fini, A. Moosavi. Energy and Buildings, 121, 265-283 (2016) DOI:10.1016/j.enbuild.2015.12.054

4. N. A. Shonina, AVOK, 6, 22-37 (2013)

5. Modular exhaust ventilation system for high-rise and industrial buildings : patent 113818 of the Rus. Federation. № 2011142710/12; decl. 21.10.2011; publ. 27.02.2012. Bull. 6., 14 p.

6. R. Saiullin, J. Kareeva, Formation and motion of droplets in gas cleaning devices with porous rotating atomizer, in IOP Conference Series: Materials Science and Engineering, 890(1), 012159 (2020) DOI:10.1088/1757-899X/890/1/012159

7. V. N. Bolomatov. AVOK, 1, 46-51 (2020)

8. A. M. Givov, P. V. Nielsen, G. Riskowski, E.O. Shilkrot., AVOK, 5, 36-47, (2001)

9. D. N. Vatuzov, S. M. Puring, Vestnik SGASU. Town Planning and Architecture, 2 (23), 14-18 (2016)

10. E. V. Osipov, L.E. Osipova. Vestnik KNITU-KHTI, 9(17), 221-223 (2014)

11. E. Osipov, R. Latyipov, L. Osipova. Reconstruction of vacuum system for crude oil vacuum tower distillation, in 2015 International Conference on Mechanical Engineering, Automation and Control Systems (MEACS), Tomsk (2015) DOI:10.1109/MEACS.2015.7414906

12. E. Osipov; E. Telyakov, S. Ponikarov. Processes, 8, 1333 (2020) DOI:10.3390/pr8111333

13. E. S. Telyakov, E.V. Osipov, D. Bugembe. Hydrocarbon processing 11(97), 61-64 (2018)

14. A. V. Khoperskov, Yu.V. Shafran, M.A. Butenko. Yujno-Sibirskii nauchnii vestnik, 2 (6), 98-102 (2014)

15. L. G. Pastukhova, S. Yu. Pleshkov, O. A. Zharovtseva, E. D. Sharkunova. Nauchnii Almanah, 12-2 (14), 134-135 (2015)

16. W. X. Chen, C. X. Huang, Y. P. Bai, D. T. Chong, J. J. Yan, J. P. Liu, International journal of advanced nuclear reactor design and technology, 2, 15-24 (2020) DOI: 10.1016/j.jandt.2020.01.001

17. X. Yang, X. Long, X. Yao, International journal of thermal sciences, 56, 95-106 (2012) DOI: $10.1016 /$ j.ijthermalsci.2012.01.021

18. J. Kareeva, K. Bliznyakova, D. Ashadullina, R. Zakieva, Influence of geometrical parameters of air inlet hole on the kinematic characteristics of jeter, IOP Conference Series: Materials Science and Engineering, 890(1), 012164 (2020) DOI:10.1088/1757899X/890/1/012164

19. W. X. Chen, J.J. Yan, D.T. Chong, J.P. Liu. Int. J. Therm. Sci., 50(8), 1554-1561 (2011) DOI:10.1016/j.ijthermalsci.2011.02.026

20. E. Rusly, A. Lu, W. W. S. Charters, A. Ooi. Int. J. Refrig., 28, 1092-1101 (2005) DOI:10.1016/j.ijrefrig.2005.02.005

21.H. A. M. Al-Ansary, S.M. Jeter. HVAC R Res. 10 (4), 521-538 (2004) DOI: $10.1080 / 10789669.2004 .10391118$

22. K. Pianthong, W. Seehanam, M. Behnia, T. Sriveerakul, S. Aphornratana. Energy Convers. Manag., 48, 2556-2564 (2007) DOI:10.1016/j.enconman.2007.03.021 